\title{
Aiming for minimally invasive treatment of pediatric acute appendicitis in a district hospital
}

Toshiro Kimura ${ }^{1,2^{*}} \mathbb{D}$, Yoshikazu Toyoki ${ }^{1}$, Aika Ichisawa', Takahiro Yamada', Yusuke Wakasa', Hiroyuki Jin', Makoto Nakai ${ }^{1}$, Kazunori Aoki ${ }^{1}$, Hiroaki Kawashima ${ }^{1}$ and Masaaki Endo ${ }^{1}$

\begin{abstract}
Background: Appendicitis is the most common cause of acute abdomen. Although emergency surgery used to be the standard treatment for both simple and complex appendicitis, there are now options for interval surgery, laparoscopic surgery, and even non-surgical treatment. In this study, we aimed to establish better treatment strategies for pediatric acute appendicitis and to find out whether minimally invasive treatment is superior to the traditional open approach. We retrospectively reviewed the cases of acute appendicitis treated in our hospital during the period from 2013 to 2018. The patients who underwent appendectomy were divided into four groups. Group 1 underwent early appendectomy with open approach, group2 underwent interval appendectomy with open approach, group 3 underwent early appendectomy with laparoscopic approach, and group 4 underwent interval appendectomy with laparoscopic approach. In addition to the above groups, the non-surgical treatment group was also studied. Clinical presentation, laboratory findings, imaging results, operative time, morbidity, and length of hospital stay were reviewed.

Results: One hundred six children's records were reviewed. Thirty-five of them were selected for non-surgery as they were cases with no fecal stone and first onset appendicitis, and 15 of these 35 patients (42.9\%) relapsed after antibiotic treatment. As for the appendix diameter, the relapse group was significantly larger than the non-relapse group ( $p=0.007$ ). In cases of surgery, group 4 had significantly less intraoperative blood loss than group $1(p<0.001)$. Group 4 had significantly fewer postoperative complications than groups 1 and 2 [group 4 vs. group 1 ( $p=0.009$ ), group 4 vs. group $2(p=0.034)$ ]. The postoperative hospital stay in groups 2 and 4 were significantly shorter than group 1 [group 1 vs. group $2(p=0.015)$, group 1 vs. group $4(p<0.001)$ ]. On the contrary, group 1 had significantly shorter total hospital stay than groups 2 and 4 [group 1 vs. group 2 ( $p=0.029)$, group 1 vs. group $4(p<0.001)$ ].

Conclusion: Interval laparoscopic appendectomy and non-surgical treatment were safe and effective in children. From the viewpoint of avoiding unnecessary emergency surgery and prolonged hospitalization, we believe that interval laparoscopic appendectomy or non-surgical treatment should be performed after identifying patients who do not require surgery, paying attention to the risk factors for relapse.
\end{abstract}

Keywords: Acute appendicitis, Children, District hospital, Interval laparoscopic appendectomy, Gasless transumbilical laparoscopic-assisted appendectomy

\footnotetext{
*Correspondence: tkimura@iuhw.ac.jp

'Department of Surgery, Aomori City Hospital, 20-14-1 Katta, Aomori, Aomori 030-0821, Japan

2Present address: Department of Pediatric Surgery, International University of Health and Welfare Narita Hospital, 852 Hatakeda, Narita, Chiba 286-8520, Japan
} 


\section{Background}

Acute appendicitis is one of the most common surgical emergencies seen in children [1]. The lifetime risk of developing appendicitis is $7.7 \%[1,2]$. Appendicitis is an inflammation of appendix. If untreated, the appendix may rupture, leading to complications such as abscess formation, paralytic ileus, and sepsis [3].

Appendectomy has been considered as an effective and safe treatment for acute appendicitis. Although urgent surgery has been considered as the standard treatment, the timing of an appendectomy varies from hospital to hospital and surgeon to surgeon [4-8]. Some perform an early appendectomy (EA), while others treat with initial antibiotics, followed by an interval appendectomy (IA) 4 to 8 weeks later. Although the latter approach is thought to reduce the complication rate and reduce the incidence of extensive resection (ileocecal resection or right hemicolectomy), a review of the literature comparing EA versus IA has shown mixed results [4, 5]. However, in recent year, the dogma that surgery is required has changed, and there are growing literatures suggesting that antibiotics without surgery may be an effective treatment for acute appendicitis in children [9-11].

Appendectomy can also be performed by open or laparoscopic techniques. Since its introduction into clinical practice in 1983, laparoscopic appendectomy (LA) has proven to be a feasible and safe procedure and has gained worldwide acceptance $[12,13]$. The advantages of LA are considered to be less postoperative pain, early discharge, less wound infection, better cosmetic results, and faster return to normal school and daily life [1420]. However, several retrospective studies, randomized studies, and meta-analyses comparing open appendectomy (OA) and LA have shown mixed results [21-25].

While there are various treatment options for pediatric acute appendicitis, it is very important to investigate safer and less burdensome treatment strategies. To establish a better treatment strategy for pediatric acute appendicitis, we compared and evaluated the outcomes of non-surgical treatment with antibiotics and surgical treatment with various methods as described above for pediatric acute appendicitis in a district hospital in terms of patient's data, operative time, morbidity, and length of hospital stay (LOS). Then, we aimed to find out whether minimally invasive treatment is superior to the traditional open approach in the treatment of children.

\section{Methods}

We included patients (age $<15$ years) who were diagnosed and treated for acute appendicitis in the Department of Surgery, at author's institute between January 2013 and December 2018. The study was performed in accordance to the ethical principles of the Declaration of Helsinki and has been approved by our hospital Ethics
Committee (reference number: 2020 - 01). The study included 106 children with a diagnosis of acute appendicitis obtained by clinical assessment and confirmed by laboratory blood tests and ultrasonography (US) and/or computed tomography (CT). We analyzed each patient's data including age, gender, white blood cell (WBC) counts, C-reactive protein (CRP) level at admission, pediatric appendicitis score, and CT findings (appendix diameter, fecal stone, and abscess formation).

According to the surgical approach, the patients were divided into four groups. Group 1 underwent EA with open approach (EOA), group 2 underwent IA with open approach (IOA), group 3 underwent EA with laparoscopic approach (ELA), and group 4 underwent IA with laparoscopic approach (ILA). In our institution, we introduced IA for the treatment of acute appendicitis in 2015 and LA in 2016. We have now introduced ILA as the standard treatment for simple and complicated cases of acute appendicitis. These four groups were compared in terms of operative time, postoperative complications (surgical site infection, paralytic ileus, remnant abscess, and others), and postoperative and total LOS. Pediatric appendicitis score [26] was calculated in all patients. Although EOA was the standard treatment for acute appendicitis before 2014, with the introduction of IA and LA, the timing and methods of surgery have changed. Currently, conservative treatment with antibiotics is the first choice, except in cases of acute pan-peritonitis or in cases of severe inflammation with extensive abscess formation at the time of initial diagnosis. Patients who started conservative treatment were treated with single or double intravenous antibiotics (cefmetazole or tazobactum/piperacillin \pm metronidazole) until WBC counts and CRP level reached almost normal and the patient became afebrile. In all cases of intra-abdominal abscesses, repeated US was routinely performed for evaluation of the abscess. If intra-abdominal abscesses increased or abdominal symptoms worsened after initiation of treatment, we performed early appendectomy during hospitalization. Since there are many reports that fecal stones are a risk factor for perforation [27] and relapse [28-31], and that the risk of relapse increases with each relapse [32], IA was not performed in cases of no fecal stones and in cases of first-onset appendicitis. IA was performed after the antibiotic treatment described above in cases with fecal stones and/or cases of relapse. As there was no clear definition for the relapse of appendicitis, we defined relapse as the recurrence of inflammation within 1 year of the initial appendicitis.

Laparoscopic procedures were performed according to a standardized technique using three trocars, one 10 $\mathrm{mm}$ and two $5 \mathrm{~mm}$, and 3-grade, 5-mm rigid scope. After achieving pneumoperitoneum, adhesion and mesoappendix were dissected and appendicular root was 
secured using two endoloops (Vicryl Endoloop-0, Ethicon Endo-Surgery, Cincinnati, Ohio, USA). Although Harmonic ${ }^{\circ}$ scalpel (Ethicon Endo-Surgery, Cincinnati, Ohio, USA) was sometimes used in cases of severe adhesions, such cases were very rare. We adopted single incisional transumbilical laparoscopic-assisted appendectomy (TULAA) [33] in a mild appendicitis without abscess formation. We developed a modified TULAA technique, gasless-TULAA, which involves lifting the abdominal wall with a retractor, without pneumoperitoneum and another incision. A $1.5-\mathrm{cm}$ vertical transumbilical incision was made within the umbilical dimpling, and wound protector was applied to the incision site. After intraperitoneal examination without pneumoperitoneum, the appendix was clamped with a 5-mm grasper and pulled through the transumbilical incision, and then appendectomy was performed.

Statistical analysis was performed by Mann-Whitney $U$ test and Kruskal-Wallis test using the Microsoft Excel for Windows Version 1908 (Microsoft Corporation). A $p$ value $<0.05$ was considered statistically significant.

\section{Results}

One hundred six children (age $<15$ years) were included in the study. Fifty-four patients underwent EA while 52 received antibiotic treatment. Of these 52 patients, 17 underwent IA according to our treatment algorithm for acute appendicitis. The mean duration from discharge to IA was 70.5 days. The remaining 35 patients were treated with antibiotics followed by no surgery. There were not any no-show patients among them, and all of them could be followed up to see whether they had relapsed or not. Fifteen of these patients had relapse of appendicitis and underwent IA after another round of antibiotic treatment (Fig. 1).

Of note, for the 35 patients who did not undergo surgery after antibiotic treatment, there were significant differences in WBC counts $\left(15.8 \times 10^{3} / \mu \mathrm{l}\right.$ vs. $11.1 \times 10^{3} / \mu \mathrm{l} ; p=$ $0.006)$, appendix diameter ( $10.3 \mathrm{~mm}$ vs. $7.8 \mathrm{~mm} ; p=0.007)$ and pediatric appendicitis score (6.3 vs. $4.4 ; p<0.001)$ between the two groups with and without relapse. There was also a significant difference in LOS between the two groups ( 7.4 days vs. 4.4 days; $p=0.015$ ). The mean appendix diameter of the 52 cases treated conservatively at our hospital was $9.6 \pm 5.1 \mathrm{~mm}$. Setting a cutoff value of 10 $\mathrm{mm}$, the percentage of cases with an appendix diameter $\geq 10 \mathrm{~mm}$ was significantly higher in the relapse group than in the non-relapse group [9/15 (60\%) vs. $1 / 20(5 \%) ; p<$ 0.001] (Table 1). Furthermore, the relapse rate was significantly higher in cases with an appendix diameter $\geq 10 \mathrm{~mm}$ [9/10 (90\%) vs. 6/25 (24\%); $p<0.001]$ (Fig. 2).

The patients who underwent appendectomy were divided into four groups. There were 49 patients in group 1, 6 patients in group 2, 5 patients in group 3, and 26 patients in group 4 . There were no significant statistical differences in demographic data (age, gender), preoperative laboratory values (WBC counts, CRP level), pediatric appendicitis score, and CT findings (appendix diameter, fecal stone, and abscess formation) between the four groups (Table 2).

In the open approach, a single incision in the lower right section (alternate incision or pararectal incision) or

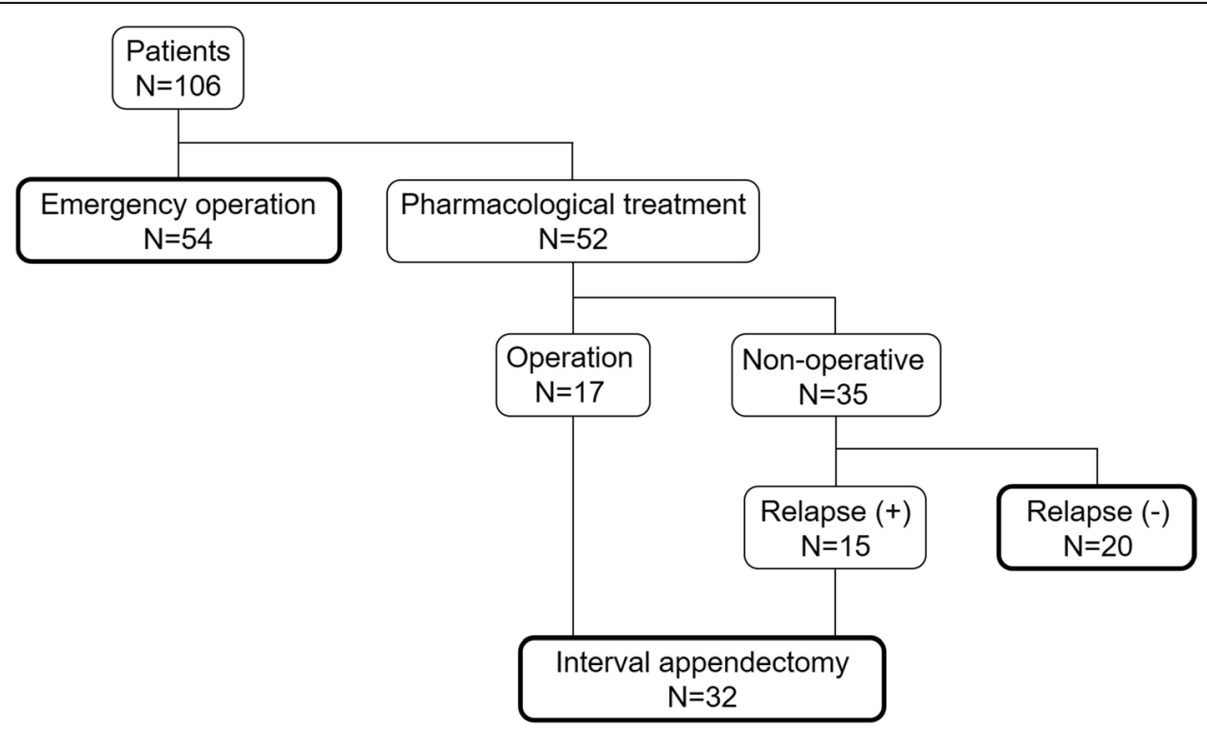

Fig. 1 Flowchart on treatment for pediatric acute appendicitis. Fifty-four (50.9\%) patients received EA while 52 (49.1\%) received antibiotic treatment. Of these 52 patients, 17 underwent IA in accordance with our treatment algorithm for acute appendicitis. The remaining 35 patients were treated with antibiotics followed by no surgery. Fifteen (42.9\%) of these patients had a relapse of appendicitis and underwent IA after another round of antibiotic treatment 
Table 1 Clinical presentation of patients without surgery after antibiotic treatment: relapse (+) vs. relapse (-)

\begin{tabular}{|c|c|c|c|}
\hline & Relapse (+) & Relapse (-) & $p$ \\
\hline$n$ (boy/girl) & $15(12 / 3)$ & $20(8 / 12)$ & 0.018 \\
\hline Age (years) (range) & $12.6 \pm 1.2(9-15)$ & $11.4 \pm 1.3(6-15)$ & 0.95 \\
\hline WBC $\left(\times 10^{3} / \mu \mathrm{l}\right)($ range $)$ & $15.8 \pm 4.6(7.5-25.0)$ & $11.1 \pm 4.8(4.1-26.4)$ & 0.006 \\
\hline CRP (mg/dL) (range) & $5.1 \pm 5.8(0.1-20.8)$ & $3.0 \pm 1.8(0.9-6.5)$ & 0.197 \\
\hline Appendix diameter (mm) (range) & $10.3 \pm 3.2(7-20)$ & $7.8 \pm 2.0(6-14)$ & 0.007 \\
\hline Appendix diameter ( $\geq 10$ mm) & $9(60 \%)$ & $1(5 \%)$ & $<0.001$ \\
\hline Pediatric appendicitis score (range) & $6.3 \pm 1.1(4-8)$ & $4.4 \pm 1.8(2-7)$ & $<0.001$ \\
\hline Length of hospital stay (day) (range) & $7.4 \pm 3.0(4-16)$ & $4.4 \pm 3.5(0-9)$ & 0.015 \\
\hline Interval to relapse (day) (range) & $99 \pm 51.1(21-204)$ & & \\
\hline
\end{tabular}

WBC White blood cell, CRP C-reactive protein

Of the 35 patients who did not have surgery after antibiotic treatment, there were significant differences in WBC counts [relapse $(+): 15.8 \times 10^{3} / \mu \mathrm{l}$ vs. relapse $(-)$ : $11.1 \times 10^{3} / \mu \mathrm{l}(p=0.006)$ ], appendix diameter [relapse $(+): 10.3 \mathrm{~mm}$ vs. relapse $(-): 7.8 \mathrm{~mm}(p=0.007)$ ] and pediatric appendicitis score [relapse $(+): 6.3$ vs. relapse $(-)$ : $4.4(p<0.001)$ ] between the two groups of patients with and without relapse. There was also a significant difference in LOS between the two groups [relapse ( + ): 7.4 days vs. relapse $(-): 4.4$ days $(p=0.015)$ ]. Setting a cutoff value of $10 \mathrm{~mm}$, the relapse group had a significantly higher percentage of cases with appendix diameters $\geq 10 \mathrm{~mm}$ than the non-relapse group [9/15 (60\%) vs. $1 / 20(5 \%) ; p<0.001]$

lower midline (median incision) was made. Each surgeon decided the incision procedure. In the laparoscopic approach, we performed gasless-TULAA in many cases safely. No open conversion was observed in groups 3 and 4 .

The mean operative time were $66.2 \mathrm{~min}$ in group 1 , $51.8 \mathrm{~min}$ in group 2, $92.8 \mathrm{~min}$ in group 3 , and $54.8 \mathrm{~min}$ in group 4 , with no statistically significant difference $(p=$ 0.061 ) as shown in Fig. 3a. There was a significant difference in intraoperative blood loss between groups 1 and 4 [group 1: $32.6 \mathrm{~g}$ vs. group 4: $3.85 \mathrm{~g}(p<0.001)$ ] (Fig. 3b). The total postoperative complication rate was $13.9 \%$ (11/ 86) in this cohort. Group 4 had significantly fewer

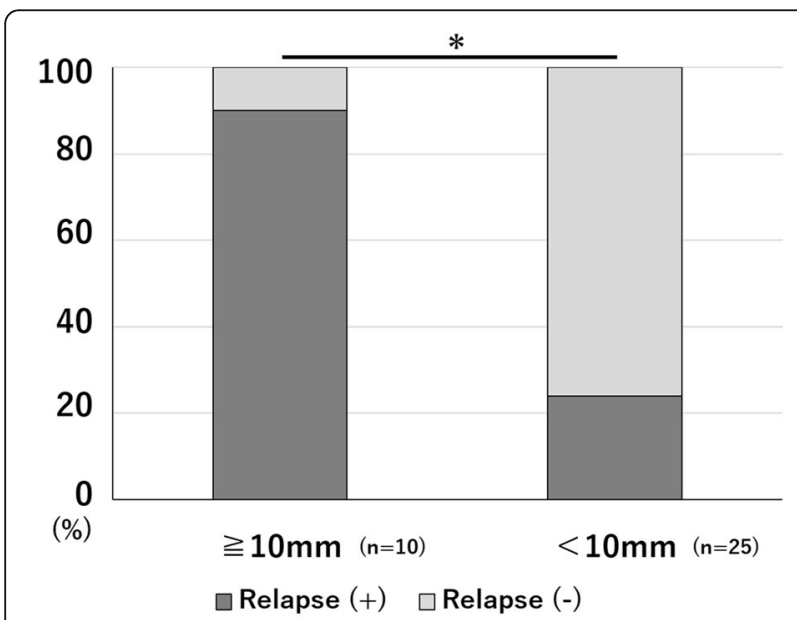

Fig. 2 Rate of relapse according to the appendix diameter. Nine of the 10 patients (90\%) with appendix diameter $\geq 10 \mathrm{~mm}$ relapsed, and 6 of the 25 patients (24\%) with appendix diameter $<10 \mathrm{~mm}$ relapsed, with a statistically significant difference between the two groups $\left({ }^{*} p<0.001\right)$ complications than groups1 and 2 [group 4: 0 vs. group 1: $11(p=0.009)$, group 4: 0 vs. group 2: 1 ( $p=0.034)$ ] (Fig. 3c).

Group 1 had significantly longer postoperative LOS than groups 2 and 4 [group 1: 7.7 days vs. group 2: 4.5 days $(p=0.015)$, group 1: 7.7 days vs. group 4: 2.7 days $(p<0.001)]$ (Fig. 4a). On the contrary, group 1 had significantly shorter total LOS than groups 2 and 4 [group 1: 10.2 days vs. group 2: 19.5 days $(p=0.029)$, group 1: 10.2 days vs. group 4: 15.5 days $(p<0.001)$ ] (Fig. $4 \mathrm{~b})$.

\section{Discussion}

In this retrospective comparative analysis, ILA in children was found to be a safe and effective surgical procedure, with a low frequency of postoperative complications and a short postoperative LOS. However, the total LOS was significantly longer in groups 2 and 4, i.e., those who underwent IA. Although there was no statistically significant difference, patients who underwent ELA had no postoperative complications and tend to have shorter postoperative and total LOS.

Several earlier studies have reported the superiority of LA over OA in terms of faster postoperative recovery $[25,34]$, lower complication rates [21,35], and shorter LOS [36, 37]. In addition, meta-analyses of several retrospective studies showed that IA was associated with fewer complications [38]. However, a recent prospective study reported that patients treated with EA had fewer adverse events than those treated with IA [5]. Another prospective study showed that EA did not significantly increase the complication rate and contributed to a decrease in radiation exposure and fewer health care visits $[5,39]$. These reports suggest that ELA may be a safer and less burdensome option for children. Several reports have recommended ELA as the standard treatment for acute appendicitis [5], and Badru et al. reported that 
Table 2 Baseline characteristics of patients undergoing appendectomy

\begin{tabular}{llllll}
\hline Group & $\mathbf{1}$ & $\mathbf{2}$ & $\mathbf{3}$ & $\mathbf{4}$ & Total \\
\hline n (boy/girl) & $49(40 / 9)$ & $6(3 / 3)$ & $5(3 / 2)$ & $26(14 / 12)$ & $86(60 / 26)$ \\
Age (years) (range) & $11.1 \pm 2.9(5-15)$ & $11.0 \pm 2.2(8-15)$ & $13.3 \pm 1.2(12-15)$ & $11.7 \pm 2.8(5-15)$ & $11.3 \pm 2.8$ \\
WBC $\left(\times 10^{3} / \mu l\right)($ range) & $16.5 \pm 5.4(6.8-31.9)$ & $15.8 \pm 2.3(13.5-19.3)$ & $13.3 \pm 2.1(9.7-14.9)$ & $15.0 \pm 4.3(5.6-23.5)$ & $15.8 \pm 4.8$ \\
CRP $(\mathrm{mg} / \mathrm{dl})$ (range) & $6.8 \pm 7.4(0.01-30.8)$ & $5.8 \pm 3.8(1.8-10.8)$ & $4.1 \pm 5.9(0.1-13.9)$ & $7.3 \pm 7.8(0.1-25.3)$ & $6.7 \pm 7.2$ \\
Appendix diameter (mm) (range) & $11.9 \pm 4.4(5-26)$ & $9.2 \pm 3.2(4-13)$ & $11.2 \pm 3.3(8-16)$ & $11.1 \pm 6.5(5-40)$ & $11.5 \pm 5.0$ \\
Fecal stone (\%) & 36 & 4 & 2 & 15 & $57(66.3)$ \\
Abscess formation (\%) & 9 & 2 & 2 & 3 & $16(18.6)$ \\
Pediatric appendicitis score (range) & $5.9 \pm 1.6(3-8)$ & $6.1 \pm 0.8(5-7)$ & $6.2 \pm 0.8(5-7)$ & $5.8 \pm 1.6(3-8)$ & $5.9 \pm 1.5$ \\
\hline
\end{tabular}

WBC White blood cell, CRP C-reactive protein

There were no significant statistical differences in demographic data (age, gender), preoperative laboratory values (WBC counts, CRP level), pediatric appendicitis score, and CT findings (appendix diameter, fecal stone, and abscess formation) between the four groups

complicated appendicitis with small abscesses and short duration of disease can be discharged early without complications with early surgery [40].

Although we did not perform appendectomy in cases without fecal stones or first-onset appendicitis, only 20 cases $(57.1 \%)$ were spared from surgery. We defined a relapse of appendicitis as a recurrence of inflammation within 1 year of initial appendicitis, and the above 20 cases did not relapse after more than 1 year of follow up. The mean duration from the initial onset to relapse in the 15 patients who with relapse was 99 days (range, 21-204 days), indicating the validity of a 1-year followup period. Although there were no postoperative complications in patients who underwent ILA, relapse is one of the perioperative complications of ILA since it is caused by prior drug treatment. Therefore, a more

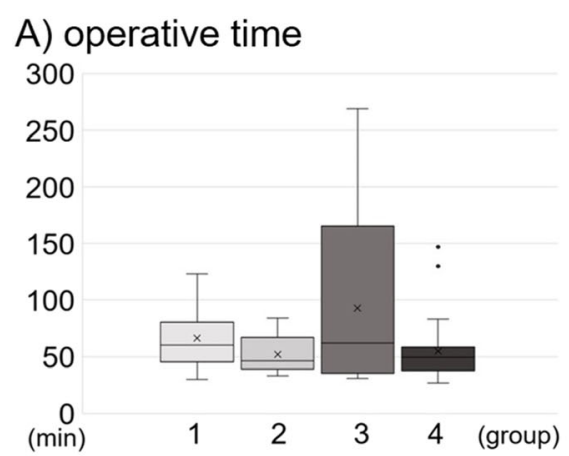

\section{B) intraoperative blood loss}

C) postoperative complication

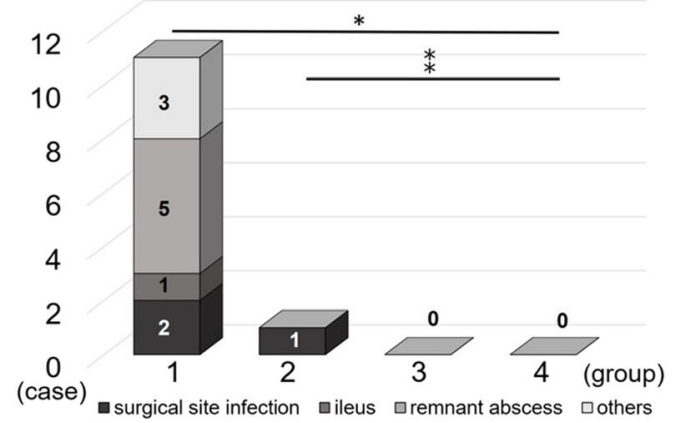

Fig. 3 Comparison of the postoperative characteristics. a Comparison of the mean operative time. The mean operative time were $66.2 \pm 25.9 \mathrm{~min}$

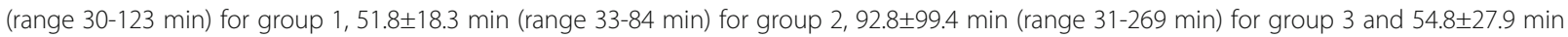
(range 27-147 $\mathrm{min}$ ) for group 4, with a no statistically significant difference $(p=0.061)$. b Comparison of the amount of intraoperative blood loss. The average value of group 1 was $32.6 \pm 66.1 \mathrm{~g}$ (range 2-255 g), group 2 was 8.33 $\pm 10.1 \mathrm{~g}$ (range 2-25 g), group 3 was $41.6 \pm 88.5 \mathrm{~g}$ (range 2-200 g) and group 4 was $3.85 \pm 9.41 \mathrm{~g}$ (range $2-50 \mathrm{~g}$ ). A significant difference was observed between groups 1 and 4 ( $^{*} p<0.001$ ). c Comparison of the postoperative complications. Group 4 had a significantly lower number of complications than groups 1 and 2 [group 4: 0\% vs. group 1: 22.4\% ( $\left.{ }^{*} p=0.009\right)$, group 4: $0 \%$ vs. group 2: $16.7 \%$ ( $\left.p=0.034\right)$ ] 

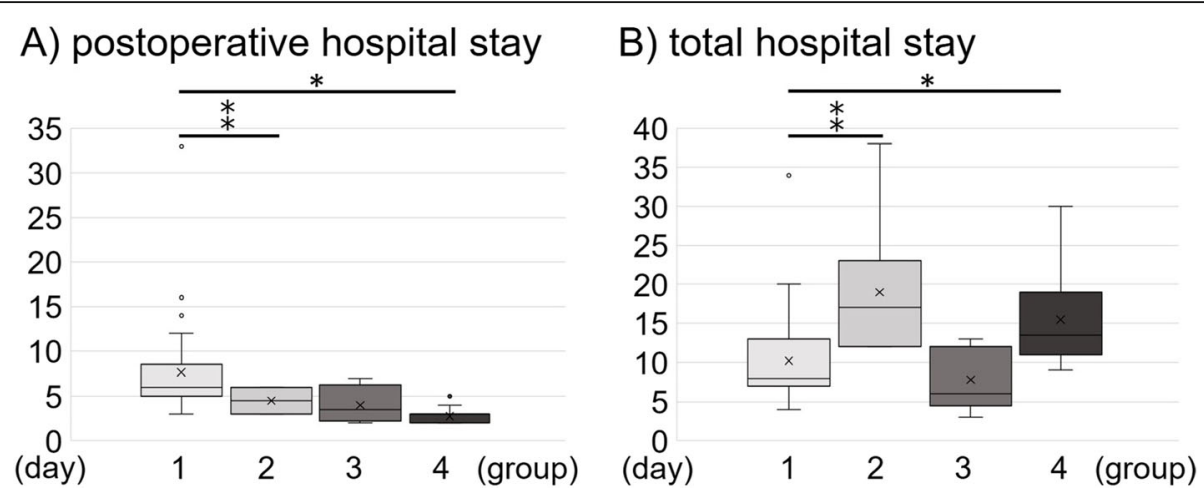

Fig. 4 Comparison of the length of hospital stay. a Comparison of the postoperative hospital stay. Mean postoperative hospital stay were $7.7 \pm 4.7$ days

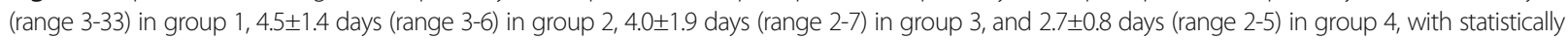
significant difference between groups 1 and 2 ( $p=0.015)$, and groups 1 and $4\left({ }^{*} p<0.001\right)$. b Comparison of the total hospital stay. Mean total hospital stay were 10.2 \pm 5.6 days (range 4-34 days) in group 1, 19.5 \pm 10.9 days (range 12-38 days) in group 2,7.8 \pm 4.1 days (range 3-13 days) in group 3, and 15.5 \pm 5.5 days (range 9-30 days) in group 4, with statistically significant difference between groups 1 and 2 ( $p=0.029$ ), and groups 1 and $4\left({ }^{*} p<0.001\right.$ )

accurate assessment of the risk of relapse of appendicitis is important to make ILA and non-surgical treatment the standard treatment strategy for appendicitis.

There have been several reports on the association between appendix diameter and relapse [41-43], and in our study, the appendix diameter was significantly larger in the relapse group. Furthermore, the relapse rate was significantly higher in patients with an appendix diameter $\geq 10 \mathrm{~mm}$, suggesting that appendix diameter may be a risk factor for relapse of appendicitis. Based on these results, we decided to add an appendix diameter $\geq 10 \mathrm{~mm}$ to the criteria for surgical indications (Fig. 5).

We had a major limitation of being a retrospective and non-randomized comparison, as it was clear that the surgical trend in the treatment of acute appendicitis at our hospital had shifted from early to interval surgery and from open to laparoscopic approach. In the IA group, cases of acute pan-peritonitis or severe inflammation were excluded,

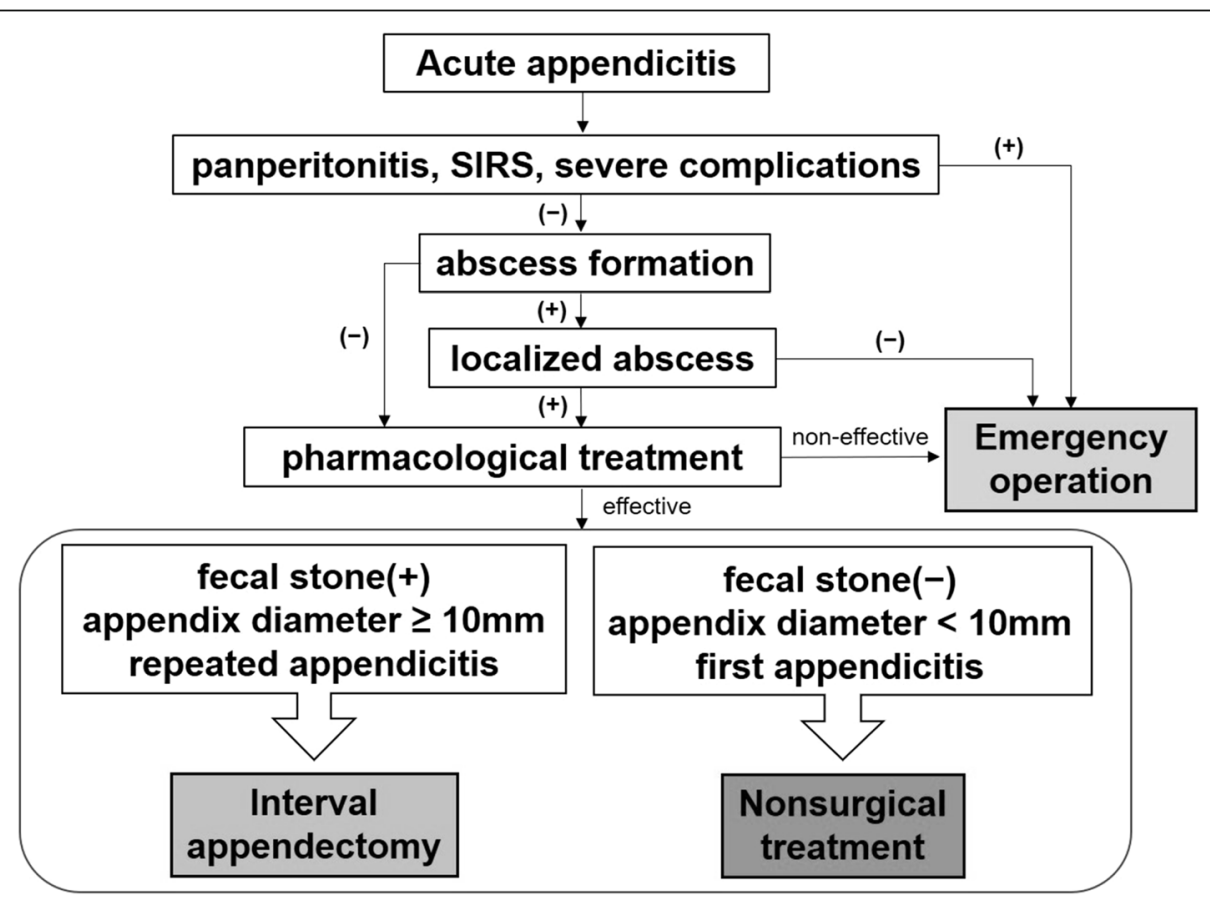

Fig. 5 Therapeutic algorithm for treatment of acute appendicitis. Conservative treatment with antibiotics is the first choice, except in cases of acute pan-peritonitis or severe inflammation with extensive abscess formation at the time of initial diagnosis. Early surgery may also be performed if it is determined that antibiotic treatment is not curative. IA is performed after antibiotic treatment in cases with fecal stones, appendix diameter $\geq 10 \mathrm{~mm}$, and recurrent cases 
while not in the EA group. Although this criterion could lead to significant bias in comparison with other groups, the effect was considered relatively small as the basic patient background was not statistically significant among the four groups, as shown in Table 2.

In addition, insufficient number of ELA cases was also considered to be one of the limitations of this study. If the number of ELA cases increases sufficiently, results showing the usefulness of ELA could be obtained. Prolonged LOS can be a heavy burden not only on the children but also on their families. In hospitals where urgent surgery is available, ELA can be the first choice of treatment, but it can be difficult in rural city hospitals. Although we had 6 surgeons who were always available for emergency surgery, we had only 2 full-time anesthesiologists, and we were not always ready for emergency surgery. In an under-staffed hospital described above, conservative treatment followed by surgery 4 to 8 weeks later is a practical strategy. Although we were unable to perform emergency surgery due to the various restrictions described above, in the future, we should consider the option of performing LA 2 to 3 days after admission.

Persistent presence of fecal stone has been reported to be associated with a significantly higher relapse rate $(66.7 \%)$ [44]. Although this indicates that the risk of relapse may vary widely depending on patient factors, metaanalyses have reported recurrence rates of 5-29\% [45] and 0-28.6\% [46] for acute uncomplicated appendicitis treated non-surgically. Considering the fact that relapse is relatively rare in patients with appendicitis treated nonsurgically at first occurrence, our strategy of treating acute appendicitis with antibiotics as a first choice and performing surgery in case of relapse seems to be appropriate.

Furthermore, non-surgical treatment has been reported to be successful in $97 \%$ of children [46], indicating the safety of antibiotic treatment for acute uncomplicated appendicitis. Most importantly, we should recognize that urgent surgery is an excessive invasion for children who may not require appendectomy.

\section{Conclusions}

We proved that ILA is safe with few postoperative complications. In addition, many children were spared from surgery, suggesting that non-surgical treatment is also a worthwhile option for the treatment of acute appendicitis. It is also very important to accurately assess the risk of relapse for further improvement of the efficacy of our current ILA and non-surgical treatment. For children, it is very important to avoid unnecessary surgery. Our treatment strategy is to treat acute uncomplicated appendicitis with antibiotics, then identify patients who do not require surgery with attention to risk factors for relapse, and then continue to perform ILA for those who are indicated for surgery.

\section{Abbreviations}

EA: Early appendectomy; IA: Interval appendectomy; LA: Laparoscopic appendectomy; OA: Open appendectomy; LOS: Length of hospital stay; CT: Computed tomography; WBC: White blood cell; CRP: C-reactive protein; EOA: Early open appendectomy; IOA: Interval open appendectomy; ELA: Early laparoscopic appendectomy; ILA: Interval laparoscopic appendectomy; TULAA: Transumbilical laparoscopic-assisted appendectomy

\section{Acknowledgements \\ We would like to thank Dr. Takeshi Hirabayashi, PhD, from Hirosaki University and Dr. Yasushi Fuchimoto, PhD, from International University Health and Welfare Narita Hospital for their assistance in editing this manuscript. We are grateful to all patients who contributed to this study and their families, as well as clinicians who helped collect patient information.}

\section{Authors' contributions}

TK and YT designed the study; TK conceptualized the manuscript and wrote the original draft; TK, Al, TY, YW, HJ, MN, KA, HK, and ME performed the data collection and analyzed the follow-up data; KA assisted in writing and editing the manuscript; $\mathrm{HJ}$ assisted in performing the statistical analysis; $\mathrm{YT}$ critically reviewed the manuscript and supervised the entire study process. All authors read and approved the final manuscript.

\section{Funding}

No funding was obtained for this study.

\section{Availability of data and materials}

The datasets supporting the conclusions of this article are available from the hospital database and the hospital record registry.

\section{Declarations}

Ethics approval and consent to participate

This study was performed in accordance to the ethical principles of the Declaration of Helsinki and has been approved by our hospital Ethics Committee (Reference number: 2020 - 01). Under the Personal Information Protection Law, which was revised and enforced in 2017, we do not need to obtain consent from research participants if the research is processed to prevent the identification of specific personal information.

\section{Consent for publication}

Not applicable

\section{Competing interests}

The authors declare that they have no competing interests.

Received: 3 December 2020 Accepted: 5 March 2021

Published online: 07 June 2021

\section{References}

1. St Peter SD, Sharp SW, Holcomb GW, Ostlie DJ. An evidence-based definition for perforated appendicitis derived from a prospective randomized trial. J Pediatr Surg. 2008;43(12):2242-5. https://doi.org/10.1016/j.jpedsurg.2008.08.051.

2. Addiss DG, Shaffer N, Fowler BS, Tauxe RV. The epidemiology of appendicitis and appendectomy in the United States. Am J Epidemiol. 1990; 132(5):910-25. https://doi.org/10.1093/oxfordjournals.aje.a115734.

3. Kurtz RJ, Heimann TM. Comparison of open and laparoscopic treatment of acute appendicitis. Am J Surg. 2001;182(3):211-4. https://doi.org/10.1016/ S0002-9610(01)00694-8.

4. Simillis C, Symeonides P, Shorthouse AJ, Tekkis PP. A meta-analysis comparing conservative treatment versus acute appendectomy for complicated appendicitis (abscess or phlegmon). Surgery. 2010;147(6):81829. https://doi.org/10.1016/j.surg.2009.11.013.

5. Blakely ML, Williams R, Dassinger MS, Eubanks JW 3rd, Fischer P, Huang EY, et al. Early vs interval appendectomy for children with perforated appendicitis. Arch Surg. 2011;146(6):660-5. https://doi.org/10.1001/archsurg.2011.6.

6. Aranda-Narváez JM, González-Sánchez AJ, Marín-Camero N, Montiel-Casado C, López-Ruiz P, Sánchez-Pérez B, et al. Conservative approach versus urgent appendectomy in surgical management of acute appendicitis with abscess or phlegmon. Rev Esp Enferm Dig. 2010;102(11):648-52. https://doi.org/1 0.4321/s1130-01082010001100005. 
7. Slusher J, Bates CA, Johnson C, Williams C, Dasgupta R, von Allmen D. Standardization and improvement of care for pediatric patients with perforated appendicitis. J Pediatr Surg. 2014;49(6):1020-4. https://doi.org/1 0.1016/j.jpedsurg.2014.01.045

8. Tsai HY, Chao HC, Yu WJ. Early appendectomy shortens antibiotic course and hospital stay in children with early perforated appendicitis. Pediatr Neonatol. 2017;58(5):406-14. https://doi.org/10.1016/j.pedneo.2016.09.001.

9. Minneci PC, Mahida JB, Lodwick DL, Sulkowski JP, Nacion KM, Cooper JN, et al. Effectiveness of patient choice in nonoperative vs surgical management of pediatric uncomplicated acute appendicitis. JAMA Surg. 2016;151(5):408-15. https://doi.org/10.1001/jamasurg.2015.4534.

10. Svensson JF, Patkova B, Almström M, Naji H, Hall NJ, Eaton S, et al. Nonoperative treatment with antibiotics versus surgery for acute nonperforated appendicitis in children: a pilot randomized controlled trial. Ann Surg. 2015;261(1):67-71. https://doi.org/10.1097/SLA.0000000000000835.

11. Armstrong J, Merritt N, Jones S, Scott L, Bütter A. Non-operative management of early, acute appendicitis in children: is it safe and effective? J Pediatr Surg. 2014;49(5):782-5. https://doi.org/10.1016/j.jpedsurg.2014.02.071.

12. Semm K. Endoscopic appendectomy. Endoscopy. 1983;15(2):59-64. https://doi.org/10.1055/s-2007-1021466.

13. McGrath B, Buckius MT, Grim R, Bell R, Ahuja V. Economics of appendicitis: cost trend analysis of laparoscopic versus open appendectomy from 1998 to 2008. J Surg Res. 2011;171(2):e161-8. https://doi.org/10.1016/j.jss.2011.06.067.

14. Ortega AE, Hunter JG, Peters JH, Swanstrom LL, Schirmer B. A prospective, randomized comparison of laparoscopic appendectomy with open appendectomy. Laparoscopic appendectomy study group. Am J Surg. 1995; 169(2):208-12. https://doi.org/10.1016/S0002-9610(99)80138-X

15. Fingerhut A, Millat B, Borrie F. Laparoscopic versus open appendectomy: time to decide. World J Surg. 1999;23(8):835-45. https://doi.org/10.1007/s002689900587.

16. Minutolo V, Gagliano G, Minutolo O, Carnazza M, La Terra S, Buttafuoco A, et al. Laparoscopic appendectomy for acute appendicitis. Chir Ital. 2009; 61(5-6):591-6.

17. Milewczyk M, Michalik M, Ciesielski M. A prospective, randomized, unicenter study comparing laparoscopic and open treatments of acute appendicitis. Surg Endosc. 2003;17(7):1023-8. https://doi.org/10.1007/s00464-002-9112-3.

18. Pedersen $A G$, Petersen $O B$, Wara P, Rønning H, Qvist N, Laurberg $S$. Randomized clinical trial of laparoscopic versus open appendicectomy. $\mathrm{Br} \mathrm{J}$ Surg. 2001;88(2):200-5. https://doi.org/10.1046/j.1365-2168.2001.01652.x.

19. Sauerland S, Lefering R, Neugebauer EA. Laparoscopic versus open surgery for suspected appendicitis. Cochrane Database Syst Rev. 2010. https://doi. org/10.1002/14651858.CD001546.pub2.

20. Wei B, Qi CL, Chen TF, Zheng ZH, Huang JL, Hu BG, et al. Laparoscopic versus open appendectomy for acute appendicitis: a metaanalysis. Surg Endosc. 2011;25(4):1199-208. https://doi.org/10.1007/s00464-010-1344-z.

21. Biondi A, Di Stefano C, Ferrara F, Bellia A, Vacante M, Piazza L. Laparoscopic versus open appendectomy: a retrospective cohort study assessing outcomes and cost-effectiveness. World J Emerg Surg. 2016; 11(1):44. https://doi.org/10.1186/s13017-016-0102-5.

22. Ciftçi F. Laparoscopic vs mini-incision open appendectomy. World J Gastrointest Surg. 2015;7(10):267-72. https://doi.org/10.4240/wjgs.v7.i10.267.

23. Masoomi H, Mills S, Dolich MO, Ketana N, Carmichael JC, Nguyen NT, et al. Comparison of outcomes of laparoscopic versus open appendectomy in children: data from the nationwide inpatient sample (NIS), 2006-2008. World J Surg. 2012;36(3):573-8. https://doi.org/10.1007/s00268-011-1417-8.

24. Faiz O, Blackburn SC, Clark J, Bottle A, Curry Jl, Farrands P, et al. Laparoscopic and conventional appendicectomy in children: outcomes in English hospitals between 1996 and 2006. Pediatr Surg Int. 2008;24(11): 1223-7. https://doi.org/10.1007/s00383-008-2247-0.

25. Tan WJ, Pek W, Kabir T, Chan WH, Wong WK, Ong HS. Clinical outcome and cost comparison between laparoscopic and open appendicectomy. Ann Acad Med Singapore. 2014;43(9):464-8.

26. Samuel M. Pediatric appendicitis score. J Pediatr Surg. 2002;37(6):877-81. https://doi.org/10.1053/jpsu.2002.32893.

27. Yokoyama Y, Saito T, Yamada A, Abe Y, Tsukada K. Clinical study of acute appendicitis with reference to factors suggesting perforated appendicitis. J Abdo Emerg Med. 2001;21(8):1369-74.

28. Amesquita M, McGillicuddy D. Recurrent appendicitis. Intern Emerg Med. 2008;3(3):251-3. https://doi.org/10.1007/s11739-008-0152-0.

29. Lugo JZ, Avgerinos DV, Lefkowitz AJ, Seigerman ME, Zahir IS, Lo AY, et al. Can interval appendectomy be justified following conservative treatment of perforated acute appendicitis? J Surg Res. 2009;164:91-4.
30. Tsai HM, Shan YS, Lin PW, Lin XZ, Chen CY. Clinical analysis of the predictive factors for recurrent appendicitis after initial nonoperative treatment of perforated appendicitis. Am J Surg. 2006;192(3):311-6. https://doi.org/10.101 6/j.amisurg.2005.08.037.

31. Rabinowitz CB, Egglin TK, Beland MD, Mayo-Smith WW. Outcomes in 74 patients with an appendicolith who did not undergo surgery: is follow-up imaging necessary? Emerg Radiol. 2007;14(3):161-5. https://doi.org/10.1007/ s10140-007-0613-1.

32. Liang TJ, Liu SI, Tsai CY, Kang CH, Huang WC, Chang HT, et al. Analysis of recurrence management in patients who underwent nonsurgical treatment for appendicitis. Medicine. 2016;95(12):e3159. https://doi.org/10.1097/MD. 0000000000003159

33. Esposito C. One-trocar appendectomy in pediatric surgery. Surg Endosc 1998;12(2):177-8. https://doi.org/10.1007/s004649900624.

34. Bartın MK, Kemik Ö, Caparlar MA, Bostancı MT, Öner MÖ. Evaluation of the open and laparoscopic appendectomy operations with respect to their on serum IL-6 levels. Ulus Travma Acil Cerrahi Derg. 2016;22(5):466-70. https:// doi.org/10.5505/tjtes.2016.47650.

35. Aly OE, Black DH, Rehman H, Ahmed I. Single incision laparoscopic appendicectomy versus conventional three-port laparoscopic appendicectomy: a systematic review and meta-analysis. Int J Surg. 2016;35: 120-8. https://doi.org/10.1016/j.jisu.2016.09.087.

36. Karakuş OZ, Ulusoy O, Ateş O, Hakgüder G, Olguner M, Akgür FM. Conventional single-port laparoscopic appendectomy for complicated appendicitis in children: efficient and cost-effective. J Minim Access Surg. 2016:12(1):16-21. https://doi.org/10.4103/0972-9941.171958.

37. Towfigh S, Chen F, Mason R, Katkhouda N, Chan L, Berne T. Laparoscopic appendectomy significantly reduces length of stay for perforated appendicitis. Surg Endosc. 2006;20(3):495-9. https://doi.org/10.1007/s00464-005-0249-8.

38. Cheng Y, Xiong X, Lu J, Wu S, Zhou R, Cheng N. Early versus delayed appendicectomy for appendiceal phlegmon or abscess. Cochrane Database Syst Rev. 2017. https://doi.org/10.1002/14651858.CD011670.pub2.

39. St Peter SD, Aguayo P, Fraser JD, Keckler SJ, Sharp SW, Leys CM, et al. Initial laparoscopic appendectomy versus initial nonoperative management and interval appendectomy for perforated appendicitis with abscess: a prospective, randomized trial. J Pediatr Surg. 2010;45(1):236-40. https://doi. org/10.1016/j.jpedsurg.2009.10.039.

40. Badru F, Piening N, Munoz Abraham AS, Osei H, Greenspon J, Chatoorgoon K, et al. Abscess and symptoms duration upon presentation should quide decision algorithms for early versus interval appendectomy in children. Pediatr Neonatol. 2019;60(5):530-6. https://doi.org/10.1016/.jpedneo.2019.01.005.

41. Cobben LP, de Van Otterloo AM, Puylaert JB. Spontaneously resolving appendicitis: frequency and natural history in 60 patients. Radiology. 2000; 215(2):349-52. https://doi.org/10.1148/radiology.215.2.r00ma08349.

42. Kin K, Iwase K, Higaki J, Mikata S, Miyazaki M, Kim T, et al. Follow-up study following conservative therapy for appendicitis diagnosed using CT examinations and CT findings predicting recurrence of symptoms. Jpn J Gastroenterol Surg. 2005:38(5):475-81. https://doi.org/10.5833/ijgs.38.475.

43. Maruyama T, Suda K, Ohtake M. The applicability of interval appendectomy for patients with acute appendicitis treated with conservative therapy from the viewpoint of recurrence risk factors. J Jpn Surg Assoc. 2015;76(12):28638. https://doi.org/10.3919/jjsa.76.2863.

44. Zhang HL, Bai YZ, Zhou X, Wang WL. Nonoperative management of appendiceal phlegmon or abscess with an appendicolith in children. J Gastrointest Surg. 2013, 17(4):766-70. https://doi.org/10.1007/s11605-013-2143-3.

45. Gorter RR, The SML, Gorter-Stam MAW, Eker HH, Bakx R, van der Lee JH, et al. Systematic review of nonoperative versus operative treatment of uncomplicated appendicitis. J Pediatr Surg. 2017;52(8):1219-27. https://doi. org/10.1016/j.jpedsurg.2017.04.005.

46. Georgiou R, Eaton S, Stanton MP, Pierro A, Hall NJ. Efficacy and safety of nonoperative treatment for acute appendicitis: a meta-analysis. Pediatrics. 2017;139(3):e20163003. https://doi.org/10.1542/peds.2016-3003.

\section{Publisher's Note}

Springer Nature remains neutral with regard to jurisdictional claims in published maps and institutional affiliations. 